\title{
The Impact of Human Papilloma Virus Among Sexually Active Youths and Suggested Primary Preventive Strategies
}

\author{
Josephine Ebomoyi Ph.D., MSPH, M(ASCP) \\ Northern Illinois University, \\ 1425 W Lincoln Hwy Dekalb Il 60115. \\ William Ebomoyi Ph.D. \\ Chicago State University, \\ 9501 Dr. Martin Luther King Jr.Dr. Chicago Il 60619
}

\begin{abstract}
The objective of the research was to assess the awareness of college age students about HPV variants and to determine suggested primary preventive strategies by respondents. The study also explored health education approach to create more awareness about the disease. HPV is one of the common sexually transmitted infections worldwide. It is linked to several cancers such as cancer of the cervix, vagina, vulva, head and neck, anal, and penile carcinomas. The instrument utilized was a questionnaire administered to students with the cooperation of other instructors. Of the 265 students surveyed, 180 were females and 73 were males. Many participants (84.5\%) had heard about HPV. However, not all were aware of the numerous variants of the virus and the link to cancer. Regarding the knowledge about different variants of HPV, 33\% of the subjects were not aware. Those respondents who thought the variants were more than 10 were 54\%. Only $10 \%$ of the participants thought there were 11-20 variants. Majority of the subjects $(61.8 \%)$ chose abstinence as a primary preventive strategy while $31.3 \%$ chose condom. The implications of our investigation were discussed and recommendation for health and wellness information is emphasized.
\end{abstract}

Key words: Human Papilloma Virus, Sexually transmitted infections, Primary prevention

\section{INTRODUCTION}

Human Papilloma Virus (HPV) is a DNA non-enveloped virus that belongs to the family Parpovaviridae (1). It measures about $55 \mathrm{~nm}$ in diameter and has an icosahedral-shaped protein capsid. It is this capsid that enfolds the circular, double-stranded DNA. It is made up of a genome of approximately 7,900 base pairs (2). HPV does not grow in tissue culture or lab animals. Its presence can be detected using Molecular techniques. Based on molecular methods that target the outside capsid protein, more than 100 types of HPV have been identified (1)

Worldwide, epidemiologic studies show that HPV is one the most common sexually transmitted infection (STI) in the world (1). According to Center for Disease Control (CDC), HPV is known to increase the risk of cervical, vulvar, vaginal, penile, oropharyngeal, anal, and rectal cancers (1). This occurs because persistent infection with one of the oncogenic HPV variants has been reported as a precursor for cancer morbidity and mortality (2). In the United. States, data from 2008-2010 show that, 38,793 HPV-associated cervical cancers were diagnosed. Studies show that more Black and Hispanic women are infected by HPV-associated cervical cancer than women of other races or ethnic groups (3). Better education of students (18-25) has been suggested for topics such as HPV and vaccines in other studies $(4,5$, and 6). There is no cure for HPV and infected individuals may not have symptoms, hence the increased number of infected people in the United States. 
In a study that used archived tissues of cancer patients in the U.S from 1993 to 2005, (7), HPV detected in $90 \%$ of cervical cancer, $91 \%$ of anal cancer, $75 \%$ of vaginal, $70 \%$ of oropharyngeal cancer and $68.8 \%$ of vulva cancers. Most people are infected with HPV after the onset of sexual activity. Up to 6.2 million people become infected with this virus annually. Statistically, an estimated $80 \%$ of sexually active individuals are most likely infected in the U.S $(4,8)$.

In the U.S. alone, 79million individuals are estimated to be infected and approximately half of those infected have reoccurring infection before age 24 (9). It is estimated that more than 9000 cases of HPV related cancers occur in men annually; responsible for $63 \%$ of penile infection, 91\% of anal and 72\% of oropharyngeal cancer. Among the cancer-related impact of HPV infection, cervical cancer is the most frequent outcome, with over 500,000 new cases and 275,000 attributable deaths world-wide in 2008 (1,7). Table 1 shows a list of HPV associated diseases.

\section{Detecting the presence of HPV}

This involves detection of different HPV variants and genetic structures. Up to 90\% DNA basepairing homology in specific regions (usually coding areas) is required to determine same type of virus. If there is more than a $10 \%$ difference in its genetic structure compared to a genome of a different HPV virus type, it will be classified as a different variant. Using this method, up to 100 Viral HPV have fully identified. Forty types are known to be associated with sexual transmission. $(1,10)$

Table 1: Human Papilloma virus (HPV) associated diseases by site*

\begin{tabular}{|l|l|}
\hline Site & Associated diseases \\
\hline Anogenital & $\begin{array}{l}\text { Anogenital warts } \\
\text { Cervical, vulvar, perinatal intraepithelial neoplasia } \\
\text { Carcinoma of the cervix, vulva, anus, penis }\end{array}$ \\
\hline Respiratory tract & $\begin{array}{l}\text { Recurrent respiratory papillomatosis } \\
\text { Squamous cell carcinoma of the larynx, tonsils } \\
\text { Tongue base, sinuses, lung }\end{array}$ \\
\hline Skin & $\begin{array}{l}\text { Deep plantar warts } \\
\text { Common warts } \\
\text { Butchers' warts } \\
\text { Carcinoma and Keratosis and epidermodysplasia } \\
\text { verruciformis }\end{array}$ \\
\hline Other & Conjunctival papillomatosis \\
& Oesophageal cancer \\
& Various carcinomas associated with immunodeficiency and \\
& HIV -related infections \\
\hline
\end{tabular}

*Adapted from Graham, S Human papillomavirus: gene expression, regulation and prospects for novel diagnostic methods and antiviral therapies, Future Microbiol. 2010 0ct; 5(10): 14931506.

\section{Categories of Genital HPV types:}

There are two categories; Low-risk HPV and High-risk HPV.

\section{Low risk $\mathrm{HPV}$}

The low risk HPV consist of the following: types: 6, 11, 42, 43, 44, 54, 61, 70, 72, and 81. These variants can cause genital lesions and are considered non-carcinogenic types. They are not associated with cancerous lesions. They are rarely associated with precancerous lesions. 
Virologists have suggested that type 6 and 11 are common etiologic agents of genital condylomas (genital warts) up to $90 \%$ cases (1).

\section{High-risk HPV}

Types $16,18,31,33,35,39,45,51,52,56,58,59,68,73$, and 82 are known to be associated with cervical as well as other anogenital cancers. These are referred to as the carcinogenic or oncogenic HPV types. HPV types 16 and 18 are most commonly isolated in cervical cancer. These types 16 and 18 are generally referred to as oncogenic HPVs. It is important to emphasize that infections with HPV type 16 or 18 do not always result in cancer (10).

\section{Insidious consequences of HPV variants}

Research studies (11) have shown that it can take 10-20 years from the time of an initial HPV infection until a tumor is produced. The percentage of high-grade cervical lesions that progress to invasive cervical cancer has been estimated to be $50 \%$ or less.

HPV infections often present with mild signs and symptoms or are asymptomatic and do not always progress to a disease state. Most infections spontaneously resolve within a few months without the formation of lesions. Most sexually active adults are infected at some point during their lifetime (10). Progression to invasive cancer can be prevented when subclinical HPV infection is detected early and regular examinations are performed.

Since the virus infects skin cells, HPV infections can be easily spread through direct skin-toskin contact during vaginal, anal and oral sex. Condom use reduces the risk of transmitting HPV but does not completely prevent transmission (11).

\section{HPV Genome and Proteins:}

When HPV infects host cells, several HPV DNA-coded proteins initiate cellular changes. Two such areas in the genome are the open reading frames (Portions of a genome that contain sequences of bases that can code for proteins). E1 to E7 and the late open reading frames L1 and L2. The proteins encoded by E1 to E7 regions of the genome are responsible for HPV gene regulation and cell transformation. Proteins resulting from L1 and L2 form the viral shell (11).

E6 and E7 encoded proteins are the most important HPV proteins in malignancy transformations These viral proteins work together to convert normal host cells to malignant cells. E6 proteins interact with intracellular protein p53 while E7 proteins interact with intracellular retinoblastoma $(\mathrm{Rb})$ protein. Intracellular proteins $\mathrm{p} 53$ and $\mathrm{Rb}$ regulate cellular growth. Both p53 and Rb are tumor suppressor proteins (11).

\section{Effect of Natural repair mechanism:}

When chromosomal damage occurs in normal cellular growth, p53 halts cellular growth and allows DNA repair enzymes to repair damage. $\mathrm{Rb}$ also halts cellular growth in DNA damage by inducing apoptosis (cellular death).

\section{Mutation accumulation:}

Mutations accumulate when E6 binds to p53. Mutations also accumulate when E7 binds to Rb. The natural DNA repair mechanism fails. This results in an unchecked cellular growth occurs which leads to chromosomal instability. This instability and unregulated cellular growth, has the potential of forming malignant cells. HPV infects the epithelial cells, which cover the inner and outer surfaces of the body including the skin, throat, genital tract, and anus. Once the 
epithelial cells are infected, the virus initiates the production of proteins that can interfere with normal cell function, enabling the cells to grow uncontrollably $(8,9$, and 11).

\section{Objective of the study:}

In view of the intricate and lethal consequences of this viral disease, and the periodic upsurge of new variants of HPV, this study was designed:

To assess the awareness of college age students about HPV variants

To emphasize the Impact of HPV among those infected

To determine suggested primary preventive strategies by respondents

To explore health education approach to create more awareness about the disease

\section{Study population:}

\section{MATERIALS AND METHODS}

With the cooperation of eight instructors at an academic institution, questionnaire was distributed to students and they were encouraged to complete it. The developed instrument had a reliability coefficient of 0.91 which was obtained using Spearman's rank order correlation. The inter-item reliability of this instrument has been determined by Kudar Richardson test formula (14). The survey consists of approximately 43 questions including demographics such as age, marital status, major, year in school. Students were asked not to insert any identifier on the questionnaire. Participants were eligible if they were over 18yrs old. Therefore the survey was for adults. To maintain anonymity of individual students' responses, they were informed that only combined data of the respondents would be analyzed. The completed instruments were collected from students for further analysis.

\section{Analysis:}

Students' combined data were collected, inspected and frequency statistical analysis was performed using SPSS statistical data analysis technique. Reported results from frequency analysis included age, gender and suggested primary preventive strategies to avoid HPV infection.

\section{Results:}

Of the 300 questionnaires distributed to the potential participants, 265 were returned completed. The response rate was $88 \%$. Of the 265 respondents, there were 180 females and 73 males. Majority of the respondents $(84.5 \%)$ have heard of HPV. With regards to knowledge about the numerous variants of HPV, $33 \%$ were not aware. Respondents who thought there were 1-10 variants whereas were $54 \%$ while only $10 \%$ thought there were 11-20 variants.

Table 2 illustrates the suggested strategy for HPV prevention among respondents by age

Table 2: Respondents' Suggested strategies for HPV prevention by age

\begin{tabular}{|c|c|c|c|c|c|}
\hline Preventive strategies & $<20$ & $20-24$ & $25-29$ & $\begin{array}{l}30 \text { and } \\
\text { above }\end{array}$ & Total \\
\hline Abstinence & 59 & 53 & 18 & 32 & $\begin{array}{c}164 \\
(61.8 \%)\end{array}$ \\
\hline Use of condom & 33 & 33 & 8 & 9 & $83(31.3 \%)$ \\
\hline $\begin{array}{l}\text { Contact/sex only with } \\
\text { trusted partner }\end{array}$ & 3 & 3 & 0 & 0 & $6(2.26 \%)$ \\
\hline Not sharing clothing & 2 & 0 & 0 & 0 & $2(.7 \%)$ \\
\hline $\begin{array}{l}\text { Disinfecting toilet seats } \\
\text { before using them }\end{array}$ & 0 & 1 & 0 & 0 & $1(.3 \%)$ \\
\hline Total & $\begin{array}{c}97 \\
(\mathbf{3 6 . 6 \% )}\end{array}$ & $\begin{array}{c}90 \\
(33.9 \%)\end{array}$ & $\begin{array}{c}26 \\
(9.8 \%)\end{array}$ & $41(\mathbf{1 5 \%})$ & \\
\hline
\end{tabular}




\section{DISCUSSION}

Young adults who are in college and away from home should be exposed to didactic health education which focuses on abstinence and possible use of condom to avoid HPV and other sexually transmitted diseases. Studies on nuns showed that HPV was not detected among them (15) which reveal that abstinence is a major preventive strategy as our study indicates. Faithful monogamous relationship with a known acquaintance and condom use will also reduce the incidence of infection. Molecular diagnostic techniques known to characterize numerous variants should be made available to laboratories not only in urban communities but in rural areas where most at risk school age students might be exposed to the possibility of getting infected from their unsuspected school age contacts who might be carriers of any of the variants of HPV.

A good percentage (31\%) chose condom as a primary prevention. Unfortunately, this STI cannot be completely prevented with condom. It is one of the sexually transmitted infections that have been linked to many cancers because of available innovative molecular studies.

Since majority of our study participants are currently not aware of existing variants (up to 100), of HPV, abstinence education will be quite crucial to eliminate or significantly reduce the incipient onset of HPV among school age students.

\section{CONCLUSION}

HPV is very virulent. New scientific technology has revealed multiple variants. Although few HPV infections have been directly related to cancer, the interaction of the non variant types with p53 gene chromosome is not fully understood. The mechanism of how p53 binds both lethal and benign variants is not fully understood. Sexual promiscuity is a major risk factor for the oncogenic variants. If cancer caused by HPV is not treated, the ultimate outcome could be death. However, CDC has vaccines recommended for 11-26 age groups. Our study shows that none of the participants were aware that, there were up to $100 \mathrm{HPV}$ variants. It also shows abstinence is the best primary preventive strategy.

The epidemiologic impact of HPV has existed for years. But it was not known because of inadequate technological resources. Innovative genomic technology recently developed, based on the technological breakthrough from human genome sequencing by March 25th 2003 led scientists to succeed in mapping out the comprehensive genome of over 100 variants of HPV. Many molecular methods of detection are now available (16) and it has recently been documented that the number of variants keeps increasing.

\section{RECOMMENDATION}

We believe that it is imperative that a course on personal health and wellness be mandatory for all students in 4 year colleges. Every student deserves to understand thoroughly the impact of STI. Students who are enrolled in year colleges are individuals of child bearing age and majority them are sexually active. The several literature reviewed for this study, show that infection can spread from skin to skin and therefore, condom does not completely prevent HPV infection. Linking such a course to the importance of self esteem as a predictor of positive outcomes may encourage students to stay more focused on their chosen career path and they will be able to make informed decisions. It provides opportunity to extend healthy habits and awareness to others including their young siblings and their children. Recently, a new vaccine has been developed and the age group that can benefit from it has been extended to 45 (17). 
ETHICAL STATEMENT

Permission was sought to administer this study at an urban academic institution in Chicago. An IRB was sought and approved by the institution.

\section{ACKNOWLEDGEMENT}

We thank the instructors that cooperated with us to collect data from their students. We also thank the volunteers that participated in the study.

\section{References:}

Centers for Disease Control and Prevention. Cancers Associated with Human Papillomavirus, United States2010-2014. USCS data brief, no 1. Atlanta, GA: Centers for Disease Control and Prevention. 2017. Accessed March 18, 2019. https://www.cdc.gov/cancer/uscs/about/data-briefs/no1-hpv-assoc-cancers-UnitedStates-20102014.htm.

Ramirez-Fort, K Khan, F Rady, P Tyring, S : Human Papillomavirus: Bench to Bedside. Curr Probl Dermatol. Basel, Karger, 2014; 45, 1-18.

Centers for Disease Control and Prevention. HPV- Associated cancer Rates by Race and Ethnicity, 2011-2015. Accessed March 22, 2019. https://www.cdc.gov/cancer/hpv/statistics/race.htm

Veins, L Henley, S Watson, M: Papilloma virus-Associated Cancers - United States 2008-2012. MMWR Morb Mortal Wkly Rep 2016; 65:661-666. Accessed 5-10-18 http://dx.doi.org/10.15585/mmwr.mm6526a1.

Lowry, D Schiller, J: Reducing HPV-associated cancer globally. Cancer Prevention Research (Philadelphia) 5(1):18-23Accessed 5-23-18. [PubMed] 2012, Abstract.

Blodt, S Holmberg, C Muller-Nordhorn, J Reckmann, N: Human Papilloma Virus awareness, knowledge and vaccine acceptance: A survey among 18-25 year old male and female vocational school students in Berlin, Germany European Journal of Public Health, 2011, 22, 6, 1 P 808. https://www.ncbi.nlm.nih.gov/pubmed/22199161

Graham, S: Human papillomavirus: gene expression, regulation and prospects for novel diagnostic methods and antiviral therapies, Future Microbiol. 2010 0ct; 5(10): 1493-1506. Accessed March 182019.

https://www.ncbi.nlm.nih.gov/pubmed/21073310.

Ebomoyi, W Ebomoyi, J: Genomic Epidemiology of Human Papillomavirus and the Adoption of Health Belief Model to Explicate Compliance with the Prophylactic Vaccine, J. Basic. Appl. Sci. Res., 3(2)1063-1069, 2013. https://www.textroad.com/pdf/JBASR/J.\%20Basic.\%20Appl.\%20Sci.\%20Res.,\%203(2)1063-1069,\%202013.pdf

Han, J Beltran, T Song, J Song, J, Choi, S: Prevalence of Genital Human Papillomavirus Infection and Human Papilloma virus Vaccination Rates Among US Adult Men National Health and Nutrition Examination Survey(NHANES) 2013-2014. https://www.ncbi.nlm.nih.gov/pubmed/28114440

Nwokolo, N Barton, S. Sexually transmitted diseases of the vulva. Ridley's The Vulva, Third Edition. 2009;6:44-70. https://www.ncbi.nlm.nih.gov/pmc/articles/PMC4830161/ Saraiya, M Unger, E Thompson, T Lynch, C. Hernandez, $\underline{B}$ Lyu, $\underline{C}$ Steinau $\underline{M}$, et al: US Assessment of HPV Types in Cancers: Implications for Current and 9Valent HPV Vaccines, L Natl Cancer Inst. 2015 Jun; 107(6): djv086.

https://www.ncbi.nlm.nih.gov/pubmed/25925419

Baseman, J and Koutsky, L: The Epidemiology of Human pappilomavirus Journal Clinical Virology 32 Supplement 18-24, 2005. https://www.ncbi.nlm.nih.gov/pubmed/15753008.

Boshart M, Gissmann L, Ikenberg H, Kleinheinz A, Scheurlen W, zur Hausen H: A new type of papillomavirus DNA, its presence in genital cancer biopsies and in cell lines derived from cervical cancer. EMBO J 1984; 3: 1151-1157. https://www.ncbi.nlm.nih.gov/pmc/articles/PMC557488/

Kuder, G Richardson, M: The theory of the estimation of test reliability. 1937, Psychometrika, 2(3), 151160 .

DiMaio, D: Nuns, Warts, Viruses, and Cancer, Yale I Biol Med. 2015; 88(2): 127-129. https://www.ncbi.nlm.nih.gov/pubmed/26029011

Bansal, A Singh, M Rai, B : Human papillomavirus-associated cancers: A growing global problem Int I Appl Basic Med Res. 2016 Apr-Jun; 6(2): 84-89. https://www.ncbi.nlm.nih.gov/pubmed/27127735

Associated press release; FDA expands use of an HPV vaccine up to age 45; Accessed March 21, 2019

https://www.statnews.com/2018/10/06/fda-expands-hpv-vaccine-use-to-age-45 